\title{
NEW DYNAMICS OF RISK AND RESPONSIBILITY: EXPANDING THE VISION FOR ACCIDENT COMPENSATION
}

\author{
Richard Gaskins*
}

A holistic approach towards risk management must recognise the interconnectedness of economic and social structures. In this article, Gaskins focuses on the concept of "network societies", which look to increase communication and organisation within their sphere of influence. While recognising that networks have the ability to regulate the distribution of risk across economic groups in society, Gaskins highlights the potential for networks to displace risk onto vulnerable sectors, thus essentially increasing risk levels for those outside the network. In the realm of health and safety, this can push the responsibility for occupational accidents onto already burdened families and communities. The development of the ACC system in New Zealand originally embraced a coherent approach to risk management. Gaskins argues that this approach has become displaced, and should be re-established as the foundation of the ACC system. This article does not attempt to prescribe a way forward for ACC, but rather aims to highlight areas of particular concern, which require consideration in relation to the further development and advancement of ACC in New Zealand.

\section{NEW APPROACHES TO RISK AND RESPONSIBILITY}

In the coming decades, public policy debates are destined to place new emphasis on the twin concepts of "risk" and "responsibility". These two pivotal terms, taken together, may indeed connect a wide range of policy challenges across a number of fields: economic policy, health and the environment, social security and public welfare. At a time when policy regimes in many countries appear to be drifting between neo-liberal renunciation and "third-way" meliorism, the need has never been greater for powerful unifying themes and perspectives.

* Professor of American Studies and Director of Legal Studies, Brandeis University (Massachusetts, United States of America). 
This potential shift in policy vision rests on volatile social and economic conditions in a complex and interdependent world. Among those conditions are new patterns of risk arising in the developed countries of Western Europe, North America and the Pacific Rim, posing a set of common challenges that transcend national policy differences. These new patterns have been studied by sociologists and economists as part of a broader theory of "network societies", which I will use as the basis for this paper. The network model calls for extending our concepts beyond familiar definitions: the concept of "risk" must break through its narrow analytic boundaries, just as "responsibility" has to move beyond abstract ethical reflection. An intriguing starting point for such expansive definitions may be found in the original vision for the New Zealand Accident Compensation scheme. ${ }^{1}$ My purpose here is to connect that earlier vision to impending policy challenges facing all "network societies".

By emphasising the complex nature of these future challenges, I mean to take an entirely fresh look at what Accident Compensation might offer to public policy. For the moment let me put aside contemporary New Zealand debates and dwell on broader issues related to new categories of social risk. So herewith a word of caution about the turbulent history of Accident Compensation ("ACC"), which was the topic of an earlier conference held in Wellington in August 2002. ${ }^{2}$ As a perennial source of partisan controversy, policy shifts and bureaucratic crises, ACC might seem an unlikely place to turn for expanding one's policy vision. It does not help that ACC remains something of an anomaly in New Zealand policy discussions, given its unusual history as a replacement for the injury compensation process inherited from the common law. As the earlier conference made clear, however, ACC was first conceived from an expansive vision of risk and its social consequences, even though later decades gradually narrowed that vision in a series of political adjustments. Early in its implementation, the ACC scheme became riven with conflicting goals drawn from competing political frameworks. By 2000, ACC policy and practice had moved a vast distance from its original vision, especially in its treatment of risk and responsibility. There was a steady shift away from social insurance principles to looser, market-driven tools, in which a key point of political contention was whether the system should be administered by the private market or by the State.

As the new century began, ACC remained stranded in an arid domain of political controversy. In my opinion, the major interest groups in ongoing ACC battles lost sight of economic and social dynamics that had already outstripped the standard political debate. By fighting rearguard actions to preserve ACC in its traditional structure, even its friends seemed to miss new patterns of risk and responsibility arising from changes associated with "network societies". At the outset of my paper, then, let me put aside current ACC controversies and focus on more general dimensions of social

1 New Zealand Royal Commission of Inquiry into Compensation for Personal Injury Compensation for Personal Injury in New Zealand: Report of the Royal Commission of Inquiry (Government Printer, Wellington, 1967) [Woodhouse Report].

2 See a selection of papers from this Conference published in (2003) 34 VUWLR 193-467. 
risk, leaving to the end of this paper some thoughts on impending reforms for ACC - some of which indeed show great promise. Let me also sidestep the polemics in New Zealand surrounding economic rationalism from the $1980 \mathrm{~s}$, as well as the resurgence of litigation strategies in the 1990s. When I speak admiringly of the Woodhouse vision, ${ }^{3}$ especially its innovative notion of "community responsibility", it is not from nostalgia for the pre-1980s welfare state. On the contrary, the world has changed dramatically since 1967 , and the need to look forward has never been greater.

The key structural events for my analysis are economic and social, going back to the 1970s. During that pivotal decade, economic organisations began their historic shift toward a more intense form of commercial activity now recognised as "alliance capitalism" or "network capitalism". 4 Along with this shift in economic structures there emerged new social pressures affecting family relationships, employment opportunities, health, and social welfare. ${ }^{5}$ Taken together, the economic and social changes from this period introduced qualitatively new patterns of human interaction, now commonly associated with "network societies". ${ }^{6}$ Network societies can be defined in many ways, but clearly one of their leading functions is to regulate the distribution of risk (in all its forms) among economic actors, between business and labour, and across diverse social groups. Public policy in the new century must comprehend these dynamic patterns, from which we may derive new definitions of "collective responsibility" for a host of unwanted social consequences.

These historic changes have, in my view, completely transformed the standard public-policy approaches to risk, ${ }^{7}$ which must now be reconstructed to match the conditions of network societies. Most of us are aware that the term "network" has taken on broader meanings in recent years. Networks not only connect our computers, they increasingly organise our workplace, our economy, and our public and private lives. They restructure organisations and they link together economic markets. They also govern political possibilities in the new global environment. As anyone who

3 Contained in the Woodhouse Report, above $\mathrm{n} 1$.

4 Commentary on this trend goes back at least to Michael J Piore and Charles F Sabel The Second Industrial Divide (Basic Books, New York, 1984).

5 See Martin Carnoy Sustaining the New Economy: Work, Family, and Community in the Information Age (Cambridge University Press, Cambridge, 2001).

6 For a brief introduction to the concept of "network societies" see Manuel Castells "Materials for an Exploratory Theory of the Network Society" (2000) 51 Brit J Sociology 5. Book-length treatments include Manuel Castells The Rise of the Network Society (Revised ed, Blackwell, Oxford, 2000) but see especially Dirk Messner The Network Society: Economic Development and International Competitiveness as Problems of Social Governance (Frank Cass, London, 1997).

7 For an overview of recent developments see Piet Strydom Risk, Environment and Society: Ongoing Debates, Current Issues, and Future Prospects (Open University Press, Buckingham, 2002). New approaches to risk must move beyond the analytic distinction between "risk" and "uncertainty" as formulated in Frank Knight Risk, Uncertainty, and Profit (Houghton Mifflin, Boston, 1921), which is still invoked by many mainstream economists. 
has become trapped inside an automated telephone loop knows, networks both expand our reach and limit our access. The growth of structural networks in economy and society long precedes our fascination with the internet. For at least the past three decades, information technology has been reshaping our world, opening up far-flung connections, and changing the structure of economic and social relations. ${ }^{8}$ Seen at this structural level, network societies introduce novel patterns of economic and political behaviour, along with entirely new dynamics of risk allocation.

\section{NETWORK STRUCTURES WITHIN AND AMONG ORGANISATIONS}

We encounter networks at many levels in our everyday activities. Everyone knows about social networks, to which we often turn in our personal and professional lives for support and advancement. But network structures also operate more impersonally. Within the capitalist firm, and within the old-style bureaucracy and the new state enterprise, interactive networks are replacing the traditional authority of top-down management. ${ }^{9}$ You may be weary of all the rhetoric about corporate "teamwork", but the trend is quite real. Large parts of complex organisations are abandoning old hierarchies and flattening out the organisation chart. Of course, not everyone is included in the cooperative loop; but inside the organisational network, old centres of authority are giving way to circular flows of power and information. Beyond these internal networks, outside in the competitive market some equally striking changes are occurring, which affect smaller businesses too. Under pressure of global economic forces, innovative corporations - large and small - strike up strategic alliances with diverse trading partners. This pattern has been called "alliance capitalism" and "the new production paradigm", where networks of cooperating firms seize competitive advantage over the old-style, vertically integrated corporation. ${ }^{10}$

The network "society" is a place where initiative and authority are widely distributed among diverse groups and institutions, linked together by strategic bargaining. What makes these strategic links possible on a global scale is the revolution in information technology, which invests operating authority within communications standards and practice codes. In network societies, questions about power and justice come down to the procedures for defining these key standards and codes. Often such procedures are quite mysterious, and it is especially unclear exactly who participates. Those who are excluded from network communications obviously play no role whatsoever.

8 The history is recounted in Dan Schiller Digital Capitalism: Networking the Global Market System (MIT Press, Boston, 1999).

9 For a research review see Joel M Polodny and Karen L Page "Network Forms of Organization" (1998) 24 Annual Review of Sociology 57. An important early summary appears in Walter W Powell "Neither Market nor Hierarchy: Network Forms of Organization" (1990) 12 Research Organizational Behavior 295.

10 For a range of European and American perspectives, see J Rogers Hollingsworth and Robert Boyer (eds) Contemporary Capitalism: The Embeddedness of Institutions (Cambridge University Press, Cambridge, 1997). 
New technology has had a profound impact on the structure of employment. The shift to information-guided production has now accelerated the division between two groups of workers: (1) a core employment group, creative and responsive to changing network demands, where teamwork and consultation gradually replace hierarchical structures; and (2) loose cadres of remaining workers, displaced into largely routine, low-skilled functions. Here and in the parallel service economy, the trend is toward more casual employment, obsolescence, de-skilling, and exclusion from planning networks. ${ }^{11}$

Employees in both groups (even the highly paid professionals) face turbulent future careers, which are likely to include frequent job changes, part-time work and self-employed freelancing. Many social critics have emphasised the heightened inequalities among diverse populations across the entire global economy, especially the inequality in employment conditions between the developed world and developing nations. ${ }^{12}$ Similar issues are emerging within the developed world itself, where patterns of justice in network societies start with the bare facts of access and exclusion. Even within quite broad networks, the particular operating codes may disadvantage those people who gain only token admittance.

\section{NETWORK GOALS: ORGANISATIONAL SURVIVAL AND SELF- PROTECTION}

The world is embracing networks at every level of human activity to absorb complex risk in the new global environment - an environment defined by historic shifts in technology, trade, family structure, and community life. Within this environment, networks reduce endemic risks by mobilising the exchange of information among network participants. The networked organisation gains the ability to learn from ongoing experience, and thus to take better control of its future. The notion of the "learning organisation" captures this central aspiration of networks: to master the challenge of risk, and not to remain its passive victim.

There is darker side to this story, however, when we consider how networks relate to their surrounding environment. Powerful networks reduce risk by displacing it onto other groups outside the network structure. The network society is famous for celebrating risk-takers, but clearly one way to manage risk is to insulate yourself and your allies from its harmful consequences. Like gated living communities, network systems reduce risk through an optical illusion - out of sight, out of mind. Alongside the enrichment of networks that operate as learning organisations, one must acknowledge this second, less appealing, aspect. Inside networks, risk management translates into self-protection with a double edge: you learn to reap the benefits of risk-taking, while displacing the inevitable costs onto other systems.

11 See generally Lawrence Mishel, Jared Bernstein and John Schmitt The State of Working America 2000/2001 (ILR Press, Ithaca, 2001).

12 See, for example, Ulrich Beck The Brave New World of Work (Polity Press, Oxford, 2000). 
Networks persist and grow; but the list of participants may suddenly shift without warning. Because networks are decentralised, distributed, non-traditional, and flexible, they respond well to accelerating demands for change. The system survives but the supporting cast is alarmingly dispensable. In an age of instant internet auctions, strategic partnerships can be unexpectedly shortlived. So too with employees: a sudden shift in market demand can render obsolete the learned skills, entrenched work patterns, and life-cycle needs of specific workers. Despite their capacity to adapt, networks do not invariably produce socially optimal outcomes. Immense networks, such as the Microsoft computer operating system, may develop around second-best standards, which prevail because of skilful or timely market positioning. ${ }^{13}$ Network success brings no guarantee of wider social benefit, but rather focuses on internal goals of survival and growth. Network logic excludes, without remorse, all participants who cannot serve the cause of survival. Without constant training and growth on the part of workers, their personal skills quickly tend towards obsolescence.

Within each network, the spirit of cooperation is tempered by the need for constant sacrifice among network partners. Although no-one owns or administers a network, strong elements of control and surveillance are embedded within the bargaining structure, which is guided by technical information systems and surrounded by tacit understandings. Along with everything else, working relationships inside the firm are framed by these powerful codes and standards. Individual workers can suddenly trip over these embedded structures, notwithstanding the collaborative spirit of networks and the circular flow of power. For each particular worker, the trend toward individualised tasks can impose unexpected limits, depending on how job descriptions are actually coded. The day is not far off, for example, when the genetic characteristics of employees could be coded into specific job requirements, either formally or informally. Under the banner of concern for workers' safety, employers already have the power to delve into the medical backgrounds of prospective employees - at least in some jurisdictions. We can only wonder what will become the prevailing industry standard on genetic qualifications and who will define that standard.

\section{IMPLICATIONS FOR OCCUPATIONAL HEALTH AND SAFETY}

The overriding goals of all networks are survival and growth. For the network to advance, individual partners have to master turbulent market sectors as best they can. In these dynamic markets, microeconomic efficiency always lies somewhere over the far horizon. Indeed, network survival may require inefficiency in some or all portions of the larger system. Successful networks face imperatives that supersede rational allocation of resources in a static environment, going beyond textbook models of long-run equilibrium. Networks are thus essentially different from

13 For this strategic perspective on standards, see Carl Shapiro and Hal R Varian Information Rules: A Strategic Guide to the Network Economy (Harvard Business School Press, Boston, 1999). See also Oz Shy The Economics of Network Industries (Cambridge University Press, Cambridge, 2001). 
large, vertically integrated companies. In addition to their own profits, individual firms must also be concerned with mutual relations - with maximising "sociability, approval, status, and power."14

Accordingly, no one can predict how individual firms will respond to engineered market incentives in the realm of health and safety. This goes to the heart of any discussion about safety and prevention. A thriving network alters the internal accounting strategy for each network partner. The dominant firm has no reason to internalise the future costs of accidents, if it can pass those costs onto other partners or bury them in a wave of innovation. ${ }^{15}$ For the same reasons, we cannot assume that single companies will compensate their employees for safety risks by offering wage premiums, even when those risks are known to both parties. Individual companies in network environments may simply ignore the economic messages tied to experience-rating of insurance premiums - amidst the noise of far louder market signals. Network logic distorts all these calculated economic messages, subverting the policy of trusting markets to discover an "optimal" level of health and safety.

Health and safety in the workplace are deeply implicated in this harsh network calculus. First, let us emphasise the positive side of the equation: how organisations use knowledge to reduce risk. ${ }^{16}$ As health and safety in employment reformers have demonstrated, individual firms have a golden opportunity to apply new information technologies to reduce workplace hazards. By relying on close monitoring and feedback loops, firms encourage the distribution of risk data throughout all levels of the organisation. Indeed, standard coded data can easily be distributed and compared across whole industries. This dispersion of knowledge is one important answer to bureaucratic drift and inertia: through continuous and systematic learning, companies build safety into their organisational software.

But nothing is simple in the network society, particularly when it comes to managing uncertainty. The learning process inside organisations works best in a climate of complete stability. To establish rigorous baseline data, and to ensure reliability in coding methods and feedback strategies, standard risk assessment assumes that most variables remain essentially constant. But clearly we no longer live in such a steady-state world; in most organisations the working environment undergoes constant upheaval in response to competitive market pressures. Dynamic companies within trading networks must be ready to reinvent themselves with breathtaking speed. Such innovation includes not just the constant turnover of personnel, but also the need to revise job descriptions, training programmes, production methods, raw materials, technical standards,

14 Paraphrasing Mark Granovetter "Economic Action and Social Structure: The Problem of Embeddedness" (1985) 91 Am J Sociology 506.

15 Similar arguments are presented in David M Driesen The Economic Dynamics of Environmental Law (MIT Press, Cambridge (Massachusetts), 2003) part II.

16 For a balanced summary of current debates on risk management, see Christopher Hood and David KC Jones (eds) Accident and Design (UCL Press, London, 1996). 
information systems, and management structures. The leading firms in active networks thus open themselves to ceaseless transformation. Given the constant pressure to adapt to changing markets, companies find it difficult to pause long enough to learn the important lessons of health and safety, let alone to build lasting remedies into their organisational software. More dependent firms may find even fewer opportunities to develop stable patterns.

Even where conditions for rigorous assessment can be met, the growing number of risk factors in modern work environments poses a challenge. Before they can analyse concrete data, organisations must first decide how to select and define the salient risk factors, choosing from countless and conflicting possibilities. ${ }^{17}$ In a simpler era, where innovation was not the constant rule, it seemed easy for expert risk managers to isolate a few conspicuous dangers as targets for discrete analysis.

Suppose, for example, that a firm wants to alter its production process by using a more powerful chemical solvent. It is more than likely that this new chemical carries with it a toxicological scorecard, based on prior uses, from which the company hopes to find prudent exposure levels for the average worker. Before long, however, more sensitive measuring devices become available, and soon the employer may learn that lower levels of exposure present statistically significant health risks for particular groups of workers: perhaps for those who smoke, those who are overweight, or those with a documented genetic condition. Each correlation harbours uncertainties, and all are subject to modification over time by further evidence.

Under these conditions, which risk factor should our hypothetical employer focus on? Will it be the substance itself, the degree of exposure, or the medical characteristics of workers subject to exposure? Depending on this answer, an attentive learning organisation may decide to use a completely different chemical, or to install better ventilation fans, or to exclude certain workers with elevated health risks. The learning process, by itself, is compatible with any or all of these responses. That process does not dictate the choice of risk definitions, let alone the choice of remedies. For these choices, organisations must rely on other methods, starting by default with assumptions already coded into organisational cultures. New strategies will be shaped by short-term opportunity costs within the network structure, as well as by state regulation. Given their powerful internal information systems, companies can ultimately learn to manage almost any conceivable risk. But different operating codes will end up displacing costs onto different players: either onto the suppliers of the chemical or onto workers who no longer fit the individualised job description.

It clearly makes a difference for the surrounding environment how risks are ultimately defined and managed within network systems. Some definitions may be dictated by industry standards or

17 See Stephen Hilgartner "The Social Construction of Risk Objects: Or, How to Pry Open Networks of Risk" in James F Short Jr and Lee Clarke (eds) Organizations, Uncertainties, and Risk (Westview Press, Boulder, 1992) 39. 
public regulation. But choices can also originate within the organisation by wide consultation with workers at all levels, who thereby gain an important voice in setting risk parameters. In Europe many companies use labour-management safety committees to conduct these negotiations. When such procedures are built into the network structure, they distribute internal bargaining strength more equally within the organisation. The very act of collaboration may well pay for itself, if it leads to a more satisfied and productive workforce, along with more precise baseline information.

\section{DISPLACING RISK BEYOND NETWORK BOUNDARIES}

Going beyond the coded networks inside individual firms, the problem of defining risk factors in the broader environment is even more diffuse. As a cruel reward for our growing knowledge of arcane hazards, we can now identify so many risk factors in our everyday world that no-one knows where to start the process of risk definition. In this complex environment, almost anything is potentially a cause of almost everything else. ${ }^{18}$ The general public confronts this reality every day in the press with stories about new and improbable risks to safety and health.

My favourite example comes from the United States. You may remember reading, several years back, about a safety crisis involving Ford vehicles and Firestone tyres. For years Americans had been warned that our beloved sport utility vehicles (SUVs) would flip over in the course of a simple road mishap - or even in a strong wind. The Ford Explorer model of SUV seemed to have more than its share of such flipovers. This information took on new meaning when regulators observed that defective Firestone tyres were also present in some 80 fatal accidents involving the Ford Explorer. Suddenly the television news was filled with dramatic footage of split and ravaged tyres; and all at once a simple causal chain presented itself, as the finger of blame pointed inexorably toward the Firestone manufacturer. Many millions of dollars were then expended on massive tyre recalls, and several hundred lawsuits from families of crash victims began their endless journey through the tort process - still proceeding after more than four years.

The general public seemed to lose interest in the safety problem, once the story boiled down to the familiar narrative of corporate deception. There was little press coverage, consequently, when Firestone investigators filed their competing report on what went wrong. ${ }^{19}$ Not surprisingly, that report found an intricate web of contributing causes behind the simpler press story. In particular, Firestone and Ford had been close partners in a production network, and were jointly aware that the safety of Firestone-equipped Explorers depended (among other variables) on the precise tyre pressure maintained by individual drivers. Key factors in the subsequent fatalities thus included the

18 The implications for social theory are developed by Niklas Luhmann Risk: A Sociological Theory (DeGruyter, New York, 1993).

19 Keith Bradsher "Firestone Engineers Offer a List of Causes for Faulty Tyres" (19 December 2000) New York Times New York C1. For more information on this controversy see Keith Bradsher High and Mighty: The Dangerous Rise of the SUV (Public Affairs, New York, 2002) ch 15. 
information imparted to drivers, as well as drivers' willingness to monitor tyre inflation. Adding to the complexity was the variation in individual driving styles, which seemed to influence the precise degree of harm resulting from over-inflated Firestone tyres.

The Firestone report admitted numerous defects in design and production methods at the company, but also emphasised sudden changes in Ford's design strategy, along with the normal failures of regulatory authorities to exercise standard oversight functions. With hindsight, then, the factors contributing to this spike in American roadway fatalities become multiple and synergistic. The fatalities resulted from an unplanned combination of sources involving manufacturing partners, consumers and their varied driving habits, regulatory performance, as well as background sources like highway design, weather conditions, and others. ${ }^{20}$ In the case of Ford and Firestone, the information feedback loops on product design worked well enough within the tight production network; at least in the beginning, the two companies coordinated their joint product design. But consumers, regulators, and highway designers were not brought into the same feedback loop. ${ }^{21}$ The two manufacturers used information technology to absorb certain production risks; in doing so, however, they transferred certain safety risks to the broader environment. Without the same tightly linked communications, other players could not coordinate their actions sufficiently to avoid serious injury - notwithstanding that their own habits likely played some part in the outcome.

The Firestone-Ford story illustrates a common experience we all recognise as general consumers confronting risk and uncertainty in a complex world. Our working and living environments are filled with overlapping, imponderable risk factors beyond our personal ability to comprehend. There are too many causal chains to pursue, and too many directions in which to point the finger of blame (including often pointing it toward ourselves). When definitions of risk are diffuse, it becomes impossible to assign responsibility in any singular fashion. In countries where these problems are fought out in lawsuits, much depends on how legal systems allocate burdens of proof. ${ }^{22}$ By default, the health and safety implications of complex risks are generally thrown back onto individual victims, and only partly offset by social insurance.

20 This perspective illustrates the classic model of "normal accidents" presented in Charles Perrow Normal Accidents: Living with High-Risk Technologies (New ed, Princeton University Press, Princeton, 1999). For an important survey of related sociological work, see Diane Vaughan "The Dark Side of Organizations: Mistake, Misconduct, and Disaster" (1999) 25 Annual Review of Sociology 271.

21 Indeed, Firestone admitted a failure in its system of monitoring consumer complaints, when its 1988 merger with Bridgestone Corporation led to the inadvertent separation of two databases, dealing respectively with damage claims and warranty adjustments. See Bradsher, above n 19.

22 The indeterminacy of blame is a major thesis in Ulrich Beck's works on "risk societies". See Ulrich Beck Risk Society (Sage, London, 1992). 


\section{SOCIAL RISK AS THE NORMAL BY-PRODUCT OF NETWORK SYSTEMS}

Today the greatest risk to workers and consumers may come from the background turbulence that accompanies life in network societies, including the fact that most workers can expect to fall out of the employment loop with growing frequency. The variable structure of work and the constant displacement of workers are clear examples of how organisations manage large-scale risks in the global economy. Guided by tightly organised economic networks, producers move through the vast uncharted waters of market demand, hoping to conquer dynamic markets and to establish network dominance. The successful network survives and prospers, even as the supporting personnel fall by the wayside. The constant churning inside the employment market, both for salaried managers and wage-earners, is a sorting mechanism for separating the benefits of economic risk-taking from the inevitable costs. These costs are displaced partly onto the social security sector, where they reappear as human and economic needs borne in part by social insurance. ${ }^{23}$

Large-scale market risk is thus transformed and passed onto employees and families. Workers at all levels are increasingly likely to change jobs frequently or to lose them altogether, thanks to the supreme flexibility of network economies under the "new production paradigm". For bettereducated workers with good connections, these transitions may appear in retrospect as steppingstones to greater glory and larger incomes. But the results are often grim for workers at the lower end of the wage scale, including those in casual or marginal employment. Younger workers face more obstacles to stable employment than at any point in our recent past. Along with the periodic risk of lost income, they also face upheavals in the sphere of family life, including changes in gender roles, irregular work patterns, pressures for childcare in two-earner families, not to mention increasing divorce rates. With the growing mobility of work and fragmentation of family life, community support networks likewise grow weaker. The potential benefits of network structures are conspicuously missing in these fragile spheres of family and community. ${ }^{24}$

In most countries, the social security safety net gives preferred treatment to workplace injuries, relying on increasingly artificial definitions of what is "work-related". Today the most pressing source of incapacity has shifted from traumatic injuries in machine-based production to an elusive group of physical and mental impairments associated with life in network societies. Threats to personal well-being accumulate over long periods of time and are shaped by influences both inside and outside the immediate workplace. Even the stress of workplace restructuring and job-shifting can take its toll.

For these hybrid risks (and especially for chronic health conditions of complex origin), narrow definitions of "work-related" have the effect of shifting responsibility out of the corporate network entirely, and back into the social sphere - primarily onto individuals and their families. After nearly

23 See Robert B Reich The Future of Success (Knopf, New York, 2001).

24 Among many sources, see Carnoy, above n 5. 
a century of workers' compensation programmes around the world, the singular focus on workplace health and safety may have outlived its usefulness. Threats to the health and well-being of working men and women are far more numerous outside the statutory boundaries of most national compensation programs. New Zealand anticipated this shift 35 years ago when the Woodhouse Commission made the singular case for extending principles of workers' compensation to the entire field of personal injury. ${ }^{25}$ Much of that breadth was taken away, however, by an ACC financing scheme that retained the old causal categories in setting insurance levies to be paid by employers. Over the past decade, narrow statutory concepts of "work-related" in ACC rules have recreated the profound definitional muddles experienced by other countries. Whatever its motivations, this attempt to separate workplace risk from all others was just one more exercise in risk displacement. Viewed from the standpoint of the individual citizen, one's sense of personal security can no longer be anchored in the traditional workplace.

\section{COMMUNITY RESPONSIBILITY IN NETWORK SOCIETIES}

Network systems are powerful means of channelling strong economic forces. To use the famous phrase of Joseph Schumpeter, networks must withstand the "gales of creative destruction". Networks are survival mechanisms in a world moving too rapidly for micro-management either by the regulatory state or by rational market actors. It is no coincidence that networks have flourished alongside new information technologies, which supply the powerful, autonomous structures that coordinate our complex economy. When it comes to addressing human risks such as health and safety, the network model is at once the solution and the lingering problem. As we have noted, networks display two conflicting tendencies: as learning systems they have the capacity to address complex risk, but as exclusive systems they may simply displace that risk onto their surrounding environment. Our challenge, then, is to reinforce the constructive side of networks while limiting the damage imposed on weaker institutions.

Responsibility in the network society shares the complex structural features of network systems. It acknowledges the weak connections between robust networks and their environments - a shadowy roadmap of one-directional paths along which social risks are displaced. Most important, the very notion of responsibility, defined at this level, presupposes that we can at least imagine a community or collective environment, united by something larger than economic self-interest. This public environment could conceivably be the traditional nation-state. But increasingly it reaches out to overlapping jurisdictions: to local, national, regional and global communities, as well as to the natural environment in an ecological bond with human society. Assuming that some such act of political imagination is even possible, responsibility means defining and redistributing risks so as to strengthen the community as a whole. In this sense, "responsibility" has similar duties to the novel

25 The Commission's findings were published in the Woodhouse Report, above $\mathrm{n} 1$. 
concept of "sustainability" in environmental policy - and perhaps it will prove equally elusive to define.

Let me underscore the enormous political challenge raised by this notion of collective or community responsibility. Its vision must be truly comprehensive, giving voice to groups that are excluded from more dominant networks. Communities, at this level, must have the capacity to define acceptable allocations of risk, based on social goals more comprehensive than the mere survival of prevailing networks. In the network society, community responsibility is structurally defined as normative standards encoded in the broadest, overarching political field. In order to survive - and to survive well - strong communities must harness the informational power of networks, which means adapting to flexible operating procedures and respecting the relative autonomy of constituent networks. One way to think about community responsibility at this level, borrowing phrases from a recent American study, is to imagine it as the "ultimate risk manager", ready to correct imbalances "when all else fails". ${ }^{26}$

Let me disappoint some readers by dismissing two familiar solutions to the problem of allocating social risk. For reasons far too numerous to list here, we cannot expect the political process, in its role as residual risk manger, to rewrite all the complex operating codes embedded within the layers of network systems. Regulatory bureaucracies lack standing and power to reengineer so completely our basic economic and social structures. Even if they had this power, the old command-and-control style of regulation can address only the most conspicuous layers of risk. To ensure a safer work and living environment, we must also tap the enormous learning capacities within dominant network systems. Responding to complex risk requires the intelligence of networkbased feedback and the power of information technology. Political leaders can help harness these tools, but only by working cooperatively with existing network structures.

Another false solution is to turn the whole problem of risk over to the market - in either its raw or regulated form. Along with their rational-choice comrades, market champions have never been persuasive on the topic of risk and uncertainty. The way tycoons and money managers hedge against financial risk cannot be adapted to more complex problems facing our social and natural environment. Markets dominate our economy and indeed our lives, but they are firmly embedded in a complex web of non-market relationships. It turns out that market flexibility requires oldfashioned virtues like cooperation, trust, and willingness to sacrifice, in addition to new-fashioned tools like databases and high-speed computers. ${ }^{27}$ Social risk cannot be reduced to standard market data or behaviour.

26 David A Moss When All Else Fails: Government as the Ultimate Risk Manager (Harvard University Press, Cambridge, 2002).

27 On the enduring role for State authorities in securing these changes, see Peter Evans Embedded Autonomy: States and Industrial Transformation (Princeton University Press, Princeton, 1995). 


\section{A NEW CONCEPT OF "SOCIAL COST"}

Missing from my analysis is the usual reference to cost "internalisation", which borrows the conceptual tools of market economics. Risk distribution in the network society is not a series of shadow market transactions, nor even potential transactions of the sort posited by Ronald Coase in his famous essay on social costs. ${ }^{28}$ Network logic reflects broader institutional structures in which all economic transactions are firmly embedded. Although they are constituted by rational human actors, networks impose their own autonomous logic, even though they strengthen existing social and distributional imbalances among potential bargainers. Operating codes within specific network loops constrain internal bargaining among network participants, thus erecting the economic hurdles known famously as "transaction costs", in the language of Ronald Coase and Oliver Williamson.

The Coase-Williamson "neo-institutional" school remains true to orthodox economics in locating transaction costs within the inscrutable domain of subjective utilities, thus placing such costs beyond further causal analysis. But network theory invites us to turn instead to an earlier "institutional" school in the tradition of J R Commons and J M Clark in America, and Myrdal and Lowe in Europe. On this view, networks set shifting boundaries within which economic bargainers conduct their negotiations. Networks impose their own structural dynamics on the acts of reducing or displacing the complex risks that remain endemic to modern society. Social costs thus present a series of real but uncalculated human and environmental losses - the residue of complex production processes in modern networked economies.

As with the emerging problem of global warming, we may never know precisely where and on whom these losses fall. We can assign a dollar figure only after considerable research, and only by creating a collective social perspective. This is a very different approach from the standard Pigovian or Calabresian models of internalising costs, which follow the "consumer-knows-best" axiom of modern welfare economics. In network societies, consumers (and producers too) are always "satisficing" within the constraints of network systems. In addition to enriching the information available to bargainers within network-embedded markets, we need to examine the non-contractual effects of powerful networks on their environment. An alternative institutional theory of social costs along these lines can be found in the writings of K William Kapp, a German economist writing in the 1950s and 1960s, who anticipated modern methods of environmental or societal accounting that are now unavoidable in network societies. ${ }^{29}$

\section{THE FUTURE OF ACC}

This analysis of networks leads to many conjectures about the New Zealand ACC System, but leaves little space for developing them. References to "community responsibility" are meant to

28 Ronald Coase "The Problem of Social Cost" (1960) 3 J L \& Econ 1.

29 On Kapp see his article "On the Nature and Significance of Social Costs" (1969) 22 Kyklos 334. 
recall a famous phrase from the 1967 Woodhouse Report, ${ }^{30}$ to which both followers and opponents of ACC have paid standard tribute over the decades. The radical implications of that phrase were lost, however, in the original ACC legislation, and were further dissipated in later Royal Commission reports on Social Security ${ }^{31}$ and Social Policy ${ }^{32}$ - not to mention the neo-liberal legislative changes of the 1990s. My point is emphatically not to return to the distant policies of the 1960s, but to reclaim the broad vision so effectively formulated by Woodhouse. His concept of community responsibility was a radical departure from policies then in place, especially as it anticipated the complex risk-oriented environment of network societies.

Looking to the future of ACC, let me draw several conclusions from the preceding analysis:

(1) ACC is simply one scheme within a web of policies responding to patterns of risk distribution in network societies. The future of ACC should thus be coordinated closely with future policy developments in health, environment, income support, public security, and global equity.

(2) Within this policy web, ACC should respond more broadly to patterns of risk distribution generated by network systems. Overall, one might describe the generic purpose of ACC as the public reallocation of risk. That formulation both strengthens and modifies the customary separation of ACC functions into distinct categories of compensation, prevention, and rehabilitation. As history shows, these three categories have competed for priority and emphasis within the titles of various ACC legislative revisions; but they are all tributaries of the single stream of risk reallocation. ACC began its life with a professed emphasis on prevention, while its record is rather one of institutionalising the limited function of compensation. To revive ACC, one needs to design a preventive strategy that is as bold and comprehensive in today's world as the compensation strategy was for the 1970s.

(3) Although "prevention" must play a central role in reallocating social risk, we should understand that risk is endemic to modern economies and societies. In the past three decades, much that passed as prevention was simply risk reallocation, masked by the closed logic of network systems. In this regard, such prudential goals as the "precautionary principle" need to be reframed as methods for allocating risk, rather than suggesting that social risk may be avoided altogether.

30 Woodhouse Report, above n 1, para 56.

31 Royal Commission of Inquiry in Social Security Social Security in New Zealand (Government Printer, Wellington, 1972) IV AJHR H 53.

32 Royal Commission on Social Policy Report of the Royal Commission on Social Policy (Royal Commission on Social Policy, Wellington, 1988) XII AJHR H 2. 
(4) By shifting the primary emphasis back to risk rather than just harmful outcomes, ACC would focus attention properly on network systems and their positive learning capacity. Some progress in this direction has been made in recent approaches to occupational health and safety.

(5) The world is full of unpaid social costs that fall on individuals, families, communities, public programs, developing societies and the natural environment. The question of which costs to compensate, after-the-fact, is a political one. We cannot insist on a remedy for every loss - a rhetorical ideal that could only be realised by ignoring vast areas of social costs.

(6) The principle of allocating social costs to their underlying cause ("internalising" costs) is similarly utopian. Despite the appeal of the "polluter pays" principle, the causal web behind social costs is too complex for us to identify unique causal agents. The process of defining and attributing costs is therefore a matter for public policy, and should be guided by the broader purpose of reallocating future risk. Thus the current ACC financing scheme would be abandoned, with its division into multiple funds defined by exclusive causal categories.

(7) Financial contributions to the cost of risk allocation would be based not on specific causal attribution, but rather on public decisions to reallocate the broad risks displaced by powerful networks. These costs include some compensation to victims, but more directly the costs of revising the operating codes of organisations - either through mandated regulation or self-correcting learning. Levies would be imposed on an industry-wide or network-wide basis, wherever possible, while new learning systems (encouraged by regulatory fines, as needed) would be developed by individual companies.

(8) It should be clear that the residual functions described above cannot be reduced to market decisions, and thus cannot be effectively privatised.

\section{PUTTING ACC INTO A LARGER POLICY NETWORK}

There are no simple remedies for risk displacement that occurs between powerful networks and their environment. Reducing risks solely for business enterprises may simply shift costs to weaker networks, including the social security safety net. In Australia and in the United States, business increasingly demands some kind of public relief from the growing risk of civil liability claims from injured parties. Legislators in both countries seem ready to reduce liability pressures on beleaguered companies and local authorities, but usually without estimating the unknown costs thereby shifted to individuals, families, communities, and already burdened public assistance schemes. Similar logic surrounds the last decade of ACC debates in New Zealand, even though the collective sum of accident costs (whether direct or displaced) is much harder to disguise. Employers are concerned primarily with shifting costs onto other funders of the scheme, even as the most vocal ACC critics want to shift costs somewhere beyond the actuarial boundaries of ACC. Under the framework of 
current ACC legislation, these pressures to shift costs strike me as inevitable but futile, especially when no one can pinpoint exact causes for many long-term disabilities. It is all the more important, then, for policymakers to see the entire range of social security protections as a loose network of its own. Claims excluded from ACC definitions will likely emerge elsewhere in the public system - or will otherwise be displaced onto individuals and families. Over the past two decades, after the twin shocks of Rogernomics and Ruthanasia, ACC has surely absorbed some unknown quantity of health and welfare claims cut from other parts of the security network.

In New Zealand, discussions about the future of ACC should not be constrained by older categories of risk derived from traumatic workplace injuries or automobile injuries. The future of ACC should be part of a much broader discussion about the larger social burdens displaced by strong networks onto weaker systems, including burdens placed on family life, community support, and social insurance schemes. Under relentless pressure from economic transformations, the social security safety net in most countries has been stretched ever thinner, under the mistaken impression that social equity and economic development compete with each other in a massive trade-off. Going back to that key term from environmental policy, one might say instead that economic growth is unsustainable over the longer term, until the public can strengthen social networks of family, community, and social policy.

A new policy on "prevention" should be conceived in network terms. Future initiatives for workplace safety, for example, can be modelled on prevention strategies found in the fields of public health and environmental protection. In my opinion, narrow conceptions of responsibility (especially legal standards of civil and criminal liability) point us in the wrong direction. Individual actions are deeply embedded in network structures, guided by operating codes that currently tend to displace risk outside the network. Effective strategies for safety and health must therefore cut across existing networks, broadening the content of information systems. In environmental policy these strategies are called "technology forcing": they use political authority to augment the general goals of complex industries, but let private actors summon their internal adaptive powers to implement those goals within each network system. ${ }^{33}$

The intelligence of networks must be brought to bear on diffuse health and safety risks; and for that the close collaboration of both markets and States is essential. Injuries and disease are caused by a complex web of interactive sources, which are continually reshaped by a dynamic risk environment. Any adequate response must be conceived as a joint venture between private and public networks. Responsibility must accordingly be widely distributed, and we should avoid funding formulas founded on liability standards for single firms. It is now time to move beyond the popular mantra of individualising responsibility and entrusting it to market-driven incentives. The

33 See Driesen, above n 15 
network society must learn to address the collective nature of risk. It can do so by inscribing new standards of shared responsibility into the operating codes of organisations, both private and public. 